\title{
Jus ad bellum, jus in bello, jus ex bello y jus post bellum ${ }^{1}$
}

\author{
Paola Alexandra Sierra-Zamora \\ Escuela Superior de Guerra "General Rafael Reyes Prieto" \\ Tania Lucia Fonseca-Ortiz ${ }^{3}$ \\ Universidad Católica de Colombia \\ Andrés Eduardo Fernández-Osorio 4 \\ Escuela Militar de Cadetes "General José María Córdova”
}

1 Este capítulo presenta los resultados colaborativos de tres proyectos de investigación: (1) "Ética militar en entornos complejos de seguridad y defensa: lecturas y aportes desde la experiencia de las Fuerzas Militares de Colombia”, del grupo de investigación Masa Crítica de la Escuela Superior de Guerra "General Rafael Reyes Prieto", Colombia, categorizado en B por Minciencias y con código de registro COL0123247; (2) "Mujeres de arma, seguridad y defensa nacional. Un análisis desde sus percepciones", del grupo de investigación en Ciencias Militares de la Escuela Militar de Cadetes "General José María Córdova”, Colombia, categorizado en B por Minciencias y con código de registro COL0082556, y (3) "Desafíos contemporáneos para la protección de Derechos Humanos en escenarios de posconflicto desde enfoques interdisciplinarios - Fase III", del grupo de investigación Persona, Instituciones y Exigencias de Justicia de la Universidad Católica de Colombia, categorizado en A1 por Minciencias y con código de registro COL0120899. Los puntos de vista pertenecen a los autores y no reflejan necesariamente los de las instituciones participantes.

2 PhD y magíster en Derechos Humanos, Democracia y Justicia Internacional de la Universitat de València, España. Abogada de la Universidad Católica de Colombia. Investigadora del grupo de investigación Masa Crítica, de la Escuela Superior de Guerra “General Rafael Reyes Prieto”. Orcid: https:/orcid. org/0000-0002-3146-7418 - Contacto: paola.sierra@esdegue.edu.co

3 Magíster (c) en Educación Inclusiva e Intercultural de la Universidad El Bosque. Abogada de la Universidad Católica de Colombia. Joven investigadora del grupo de investigación Persona, Instituciones y Exigencias de Justicia, adscrito al Centro de Investigaciones Socio Jurídicas de la Universidad Católica de Colombia. Investigadora del grupo de investigación Centro de Misiones Internacionales, Acción Integral y Derechos Humanos, reconocido por Minciencias. OrcID: https://orcid.org/0000-0001-5089-3562 - Contacto: tlfonseca64@ucatolica.edu.co

4 Teniente Coronel del Ejército Nacional de Colombia. PhD en Derecho y Ciencia Política de la Universidad de Barcelona, España. Magíster en Economía, Estado y Sociedad: Política y Seguridad del University College, Londres, Reino Unido. Magíster en Relaciones Internacionales del Higher School of Economics, Moscú, Federación de Rusia. Investigador del grupo de investigación en Ciencias Militares de la Escuela Militar de Cadetes “General José María Córdova”. Orcid: https://orcid.org/0000-0003-0643-0258 - Contacto: andres.fernandez@buzonejercito.mil.co 


\section{Resumen}

El presente capítulo de libro tiene como objetivo analizar el papel de los conceptos clásicos jus ad bellum, jus in bello, jus ex bello y jus post bellum en la consolidación del derecho internacional público que regula la guerra en todas sus instancias, incluso luego de su finalización o posconflicto. El trabajo aplica un método de investigación deductivo-analítico, por medio del cual se valoran los postulados doctrinales más relevantes que representan las teorías y los compendios normativos sobre la guerra justa. Se concluye que cada uno de los jus evidencia la responsabilidad internacional de salvaguardar la integridad humana en el contexto de los conflictos armados. Específicamente, el análisis del jus post bellum en Colombia demuestra que las situaciones que se presentan en el país dificultan que se cumpla el objetivo de transitar a un contexto de paz.

Palabras clave: Colombia; ética militar; jus ad bellum; jus ex bello; jus in bello; jus post bellum.

\section{Introducción}

La historia de la guerra en el mundo ha producido grandes cambios en las dinámicas políticas, económicas y legales, así como, en general, en la forma como la humanidad se desenvuelve en sociedad, pues las confrontaciones armadas cambian sustancialmente las relaciones de dominación establecidas con antelación al campo de batalla (Abello, 2003). Tales relaciones se sustentan en poderíos territoriales, hegemonías políticas y económicas que se transforman o se destruyen en razón a una disputa, en la cual el vencedor indicará cómo y de qué manera se condicionará el orden conocido en función de los intereses de un país o un grupo específico.

La relevancia que tienen las confrontaciones y los efectos de toda índole que se producen a su terminación han generado un sinnúmero de teorías en torno a su génesis, su utilidad e incluso su inexorable existencia. Entre las más relevantes se encuentra la concebida por Clausewitz (1992), quien definió la guerra como la "continuación de la política por otros medios" 5 , justo cuando

5 Junto a esta concepción se une la de Bobbio, quien define la guerra como un conflicto entre grupos políticos que confían en la violencia organizada - como un organismo preparado para el objetivo armado: Fuerzas Militares_ la solución de sus discrepancias más importantes (Bartolomé, 2017). 
las soluciones pacíficas no son suficientes. Este panorama se ha perpetuado con el pasar de los años, e incluso es conjunto a la evolución y la historia humanas (Puyana, 2003), por lo que se visibiliza como un aspecto inevitable contra el que solo se puede lograr una regulación, pero no la eliminación perenne.

Al respecto, Hegel (1968), citado por Silva (2008), plantea la inevitabilidad desde un "carácter constructivo, pero no en una óptica valorativa, sino como un accidente (necesidad) que forma parte del proceso histórico de concreción del espíritu" (p. 27). Esta perspectiva se contrapone a la estructura teórica sobre la paz perpetua propuesta por Kant (1979), que se niega a naturalizar la violencia, aunque la vivencia pacífica sea uno de los más grandes retos para la sociedad. Es decir, mientras uno de los filósofos define a la guerra como una necesidad, el otro la considera un hecho superable por el que los Estados deben trabajar, sin que la superación signifique pérdida de la soberanía, pero sí un abandono de la libertad salvaje (Santiago, 2004).

De tal suerte, la construcción conceptual y teórica alrededor de lo que se concibe como conflicto presenta diversas acepciones, las cuales no solo se adaptan a las visiones de juristas o filósofos, sino también a la época y el contexto en el que habitaron. Por esta razón, si bien no existe una visión unívoca sobre lo que verdaderamente es el conflicto armado o la guerra — con la salvedad de las posibles diferencias terminológicas entre uno y otro concepto-, sí se cuenta con un profundo estudio de los contextos y las situaciones reales en que tienen lugar.

El contexto, entonces, es una de las principales características que permiten identificar un conflicto y la manera en la que se gesta, de tal forma que es imposible calificar unánimemente los tipos de conflictos y su geolocalización. Verbigracia, si se comparan los conflictos derivados del poder (Mercado \& González, 2007) en Oriente Medio con los que ocurren en Latinoamérica, se encontrará que tienen distintos orígenes, sobre todo si se gestan entre Estados o entre grupos al margen de la ley y el Estado. En particular, la manera como se han perpetuado las guerras tiene diversos orígenes, desde la liberación de yugos absolutistas que dieron cabida a revoluciones como la francesa o las confrontaciones entre potencias que resultaron en las guerras mundiales del siglo XX — donde se le dio, entre otras cosas, fin al fascismo y al nacionalso- 
cialismo (Bosemberg, 2006)—, hasta los conflictos armados internos en los que los Estados luchan por el control territorial y el orden público alterado por los grupos al margen de la ley, como sería el caso específico de Perú con Sendero Luminoso (Gurmendi, 2013; Miron, 2020) o Colombia con las FARC-Ep (Arratia-Sandoval et al., 2020; Sarmiento-Hernández et al., 2020; Sierra-Zamora, 2020).

Por consiguiente, ante la diversificación de los momentos y los espacios en los cuales se ha gestado la guerra y, por supuesto, ante las miles de víctimas que han cobrado los hechos indiscriminados de violencia, los Estados crearon a lo largo de varias décadas algunos códigos o tratados con el fin de controlar las tropas o los territorios — según las épocas — para regular la atrocidad de los hechos violentos (Jiménez \& Jiménez, 2019). En este contexto, las ideas de Henry Dunant y Guillaume-Henri Defoe (Comité Internacional de la Cruz Roja, 2005) constituyen los primeros esbozos del Derecho Internacional Humanitario (DiH), por medio del cual se pretende humanizar la guerra (Jiménez-Reina et al., 2021), sin que ello signifique una aceptación o prohibición del conflicto, pues su esencia radica en la protección a la población civil y las víctimas, entre otros aspectos que se dilucidan con posterioridad. Conjuntamente, estos códigos de conducta frente a la guerra priorizan el cumplimiento de los postulados del DiH, el respeto por los Derechos Humanos (Dр.Нн.) y, en general, todo el conjunto que forma parte del derecho público internacional (Dip) prima facie.

Indiscutiblemente, el compendio de investigaciones sobre la guerra y cada una de sus aristas es incalculable, lo cual evidencia la importancia que reviste su estudio. Sin embargo, el objeto del presente capítulo es evaluar específicamente la regulación de la guerra y cómo se ha procurado una guerra justa por medio de los instrumentos internacionales que forman parte del Dip, el Dir y los Do.Hh. Por esta razón, este texto se centra en responder el siguiente cuestionamiento: ¿Cuál ha sido el desarrollo de la guerra justa en las teorías clásicas de regulación desde la humanización de la guerra y su avance por medio del DiH?

Para contestarla, se emplea un método de investigación deductivo-analítico que permite valorar los postulados doctrinales más relevantes y se descom- 
pone el objeto de estudio para desentrańar los aspectos preponderantes que representan las teorías y los compendios normativos sobre la guerra justa. $\mathrm{Al}$ final, se concluye con una síntesis del análisis. La investigación se desarrolla en cuatro ejes temáticos: el primero aborda los conceptos de jus ad bellum y jus in bello como la humanización de la guerra, de tal manera que se develan los componentes más influyentes en torno al DiH y lo que implica su cumplimiento. Posteriormente, el segundo eje temático describe el jus ex bello como teoría reciente que evalúa la viabilidad de ponerle fin a la guerra cuando la victoria es poco probable. A su vez, el tercer eje estudia el jus post bellum, teoría que aborda por excelencia el derecho del posconflicto y, por lo tanto, representa el escenario idóneo para analizar el caso colombiano y las dinámicas del proceso luego de la culminación de la lucha armada. Finalmente, el último eje temático trata sobre la ética militar desde la perspectiva de la guerra justa, luego de lo cual el capítulo presenta las conclusiones del estudio.

\section{Jus ad bellum y jus in bello: la humanización de la guerra}

Ante la implacable realidad de la guerra y la imposibilidad de su prohibición, las leyes y los organismos internacionales han procurado regular en gran parte los asuntos que son de prioritaria atención durante una lucha armada y cuyo desconocimiento implica desatender los principios humanos que no se pueden violentar bajo ningún argumento. Por ello, en aras de limitar los impactos nocivos a la humanidad, se ha creado una serie de teorías que buscan moderar el conflicto y obligar a los Estados o a los grupos a cumplirlos, ya sea desde la génesis de la guerra, durante ella, o a su terminación.

Específicamente, estas teorías crearon de manera inicial la pareja terminológica del jus ad bellum y el jus in bello (Kolb, 1997). El primer término hace referencia al "derecho a la guerra", por medio del cual "cualquier sociedad estaba en el derecho de iniciar un conflicto" (Cuenca et al., 2018, p. 28). A su vez, el término alude a la denominada "justicia en la guerra", que se refiere a la motivación primigenia que conduce al uso de la violencia como solución a un problema o discrepancia, pues debe ser justa y cumplir con ciertos principios: 
1. Tener una causa justa.

2. Tener recta intención.

3. Que la guerra sea declarada por una autoridad competente.

4. Que haya proporcionalidad en los medios usados.

5. Tener una posibilidad razonable de éxito.

6. Que la guerra sea el último recurso al que se acude (Ruiz, 2003, p. 1).

Se considera que la mayoría de los principios enumerados surgen a partir de un planteamiento realizado por Tomás de Aquino, en su necesidad de imponer requisitos a las sociedades sin que en ellos medien sus diferencias (Castañeda, 2003). Por supuesto, estos postulados — nacidos en una temporalidad y un contexto específicos - se alejan de las realidades de las guerras que ocurren en la modernidad, pero son un excelente referente de los aspectos necesarios para que la guerra sea tan justa como se espera. Estos límites que se pretende dar a las dimensiones de la guerra no solo se enuncian en el marco de los principios dogmáticos propuestos en el jus ad bellum, sino que también se desarrollan en verdaderos compendios normativos que regulan las acciones de los Estados y la solución de sus conflictos. Asimismo, son pertinentes en los conflictos armados internos, idea que se contrapone cuando los aspectos genéricos no son pensados desde la perspectiva estatal, sino de la beligerante (Organización de las Naciones Unidas, 2011), un estatus que ostentan las fuerzas armadas al margen de la ley cuando se reconocen, lo cual además determina su situación frente al DiH en lo que concierne al cumplimiento obligatorio de los convenios y los protocolos adicionales durante el tiempo que dure el conflicto (Vargas et al., 2013).

No obstante, los principios de la guerra justa del jus ad bellum han generado diversos cuestionamientos por cuanto sus términos parecen ser indeterminados o pueden estar condicionados por el observador: por ejemplo, para un Estado sería suficiente justificación creer que la guerra que desea iniciar es justa. Por lo tanto, en esta interpretación los criterios se subordinaban y, por ejemplo, era suficiente contar con la declaración de una autoridad competente o afirmar que la guerra conducía al restablecimiento de la paz para estimarla como justa (Grocio, 1925). 
Si bien la guerra se consideraba un derecho, el impacto que generaba $a$ posteriori cada confrontación obligó a que la Organización de las Naciones Unidas la declarara ilegal en su Carta de 1945 (artículo 2.4) y que solo fuera posible recurrir a ella en determinadas excepciones: seguridad colectiva, legítima defensa y guerras de liberación nacional. Esta decisión trascendental cambió las dinámicas de toda la teoría del jus ad bellum, pues la guerra solo se realizaría en casos extremos y se regularía cada acción con el fin de evitar desenlaces gravosos.

Ahora bien, el segundo término, jus in bello, hace referencia al "derecho en la guerra”, es decir, a las normas que determinan cómo y de qué manera se puede llevar a cabo una confrontación armada. En palabras de Walzer (2011), "el objetivo de la convención bélica es establecer los deberes que, respecto a la dirección de las hostilidades, incumben a los Estados beligerantes, a los comandantes de los ejércitos y a los soldados individuales" (p. 181). Tal convención es la hoja de ruta que guía a los ejércitos de los Estados que se enfrentan en una guerra para evitar que la lucha armada conduzca al exterminio.

De igual manera, para Rawls (1999), citado por Giraldo (2008), esta terminología de la guerra justa del jus in bello "está encabezada por un principio encaminado a mantener la dinámica bélica en la perspectiva correcta. Se trata de que la guerra pueda conducir a una 'paz justa y duradera' " (p. 53). En suma, la perspectiva de este filósofo recoge la causa justa desde la paz y las condiciones correctas para conducir el conflicto, sin demeritar lo indeseable que la guerra resulta para los Estados e incluso para la comunidad internacional.

De tal suerte, la idea de jus in bello se establece como el compendio normativo que regula cuáles son los medios y los métodos con los que se puede enfrentar la guerra, dado que no todos están permitidos, pues atentan brutalmente contra la humanidad. Esta es, precisamente, la principal intención de este derecho de la guerra, mejor conocido como DiH, el cual constituye un

cuerpo de normas jurídicas de origen convencional o consuetudinario, específicamente aplicables a los conflictos armados internacionales o no internacionales, y que limita por razones humanitarias el derecho de las partes en conflicto de elegir libremente los métodos y los medios utilizados en la guerra, evitando que se vean afectados las personas y los bienes legalmente protegidos. (Peytrignet, 1995, p. 145) 
Es así como este término se convierte en un sistema de normas integradas que buscan regular la guerra y que, una vez se ha tomado la decisión de acudir a la guerra como solución, impedirá que se atente contra la dignidad humana de las personas como principio articulador de los DD. HH., los cuales deben ser protegidos en todo momento, hasta en la guerra. Este término se comprende en principio desde dos vertientes: la primera de ellas es el derecho de La Haya, relativo a la conducción de la guerra respecto a los medios y los métodos, y la segunda es el derecho de Ginebra sobre las víctimas. Luego de que se crearan estos dos cuerpos normativos, se ha establecido un sinnúmero de componentes que protegen en mayor medida la humanidad y se constituyen como una obligación para cada uno de los Estados de la comunidad internacional o aquellos que hayan ratificado los instrumentos internacionales.

De cualquier modo, si bien los términos analizados en este apartado han sido de gran utilidad para velar por lo justo y el respeto a la humanidad en la guerra, es necesario señalar que existe una contradicción entre la prohibición de la guerra y la presencia de un conjunto de normas que la regulan, más allá de las excepciones, por lo cual desaparece la armoniosa convivencia entre uno y otro concepto, pues se contraponen. Sin embargo, esta cuestión insuperable se debe sopesar, especialmente si se considera que "el jus ad bellum formula preguntas a los líderes políticos; el jus in bello considera la responsabilidad de los soldados. Por lo tanto, una guerra justificable puede librarse injustamente; una guerra injusta puede librarse justamente" (Bellamy, 2009, p. 201). La justa razón o conducción de la guerra, aunque genera un claro desencuentro, no ha tenido más soluciones que aceptar el carácter insuperable de la guerra y procurar que sea humana, desligándose del debate sobre si su existencia es valedera.

Por supuesto, es más importante por su función el jus in bello o Diн,

en primer lugar, porque pese a que el uso de la fuerza estaba prohibido, las guerras se iban a seguir sucediendo, por lo que las reglas del ius in bello humanizaban, al menos en alguna medida, la conducción de las hostilidades; en segundo lugar, por lo dificultoso de determinar quién llevaba adelante un uso legítimo de la fuerza. (Legris, 2016, p. 40) 
Respecto a este punto hay varias cuestiones de especial relevancia. Por una parte, a pesar de la prohibición de la guerra, el Dip reconoce que los Estados tienen derecho al uso legítimo de la fuerza (tabla 1), con las excepciones en los casos que pueden sobrepasar la imposibilidad de recurrir a la guerra. Por otra, además, el Dır adiciona el uso legítimo en los conflictos internos.

Tabla 1. Tipos de uso de la fuerza legítima en el Dip

En la Carta de la ONU

En el Dir general

1. Seguridad colectiva bajo el Consejo de Seguridad.

2. Seguridad colectiva bajo las organizaciones regionales.

3. Autodefensa (legítima defensa).

4. Contra los Estados otrora enemigos.
1. Delitos sometidos a jurisdicción universal.

2. Contra el tránsito no autorizado.

3. Contra la permanencia militar no autorizada.

4. En caso de catástrofe natural incontrolable en otro Estado.

5. Contra la violación de la neutralidad.

6. En conflictos internos.

Fuente: Hernández (2000, p. 175).

Como se observa en la tabla 1 , estos cuerpos normativos permiten el uso de la fuerza en determinadas condiciones y escenarios, los cuales no se alejan del todo de las causas primarias de las guerras. En este sentido, simplemente definen los fundamentos fácticos por los cuales un Estado puede recurrir a una guerra o a un conflicto armado y, conjuntamente, lo que determina el Diн. Así, se puede afirmar que el jus in bello es un recurso vital que abandera el respeto por la humanidad, específicamente desde los primeros convenios de Ginebra de 1864 y 1948.

A la relevancia significativa del Diн se debe sumar la historia de su aparición, que se encuentra inmortalizada en el libro Un recuerdo de Solferino, en donde Dunant hace especial mención a los soldados heridos que quedaban fuera de combate y desprotegidos, pues ya no eran útiles para la guerra y los servicios médicos resultaban insuficientes para atenderlos. Testigo de esta realidad, Dunant elabora los argumentos y reúne a las personas que hicieron realidad el Comité Internacional de la Cruz Roja (CICR), el cual promovió la 
creación de los primeros instrumentos del Diн — desarrollando la teoría del jus in bello-, que agrupa la normatividad y las reglas consuetudinarias establecidas hasta ese momento ${ }^{6}$.

Ahora bien, el paso del tiempo y las nuevas discusiones que trajo el cambio generacional hicieron que el Diн no se centrara solamente en la guerra per se, sino también en cómo se manifiesta el conflicto en la sociedad. A manera de reflexión, sin embargo, cabe anotar que esta perspectiva social sobre los conflictos debe ser interdisciplinaria, pues el DiH no puede hacer estimaciones sociales sin realizar o consultar estudios de sociología que le permitan entender las dinámicas cambiantes y así responder a ellas, como sería el caso de la protesta social, que no figura como una verdadera guerra, pero es generadora de problemáticas de gran envergadura y de cambios sociales de igual magnitud.

Al respecto, Salmón (2004) sostiene que la protesta pertenece a otra forma de conflictividad que debe ser objeto de observación por parte del DiH. Específicamente, considera que se trata de conflictos de tercera generación a los que denomina conflictos de identidad o étnicos en razón al exterminio de comunidades, así como conflictos desestructurados que, según explica, tienen que ver con el failed state ${ }^{7}$ y la desaparición de las estructuras sociales. Por último, Salmón (2004) menciona los conflictos asimétricos y presenta como un claro ejemplo la lucha contra $\mathrm{Al}$ Qaeda.

Lo que se ha planteado hasta el momento en este apartado sintetiza el contenido más relevante de las teorías clásicas que pretendieron humanizar la guerra y que con el paso del tiempo articularon las regulaciones sobre las confrontaciones armadas. Por supuesto, existe una gran cantidad de aspectos para evaluar en cada característica o categoría del derecho en la guerra, como serían por ejemplo los instrumentos o su obligatoriedad. No obstante, este acercamiento a la génesis y el desarrollo del jus ad bellum y el jus in bello no solo develan la necesidad de regular los intereses estatales y de los grupos que van en contravía del orden legal, como las guerrillas, sino también la utilidad y la aplicabilidad de estos conceptos al contexto actual a través del Dir y las medidas

6 Sobre el Diн consuetudinario, véase Henckaerts (2005).

7 El estado fallido como concepto es uno de los temas con mayor debate en el mundo jurídico por la complejidad que reviste. Para mayor información, véase Flórez (2011). 
que deben adoptar los Estados en su ordenamiento interno. Por último, este análisis muestra que, si no existe un delito que se configure por el incumplimiento al jus in bello, este no podrá ser castigado como debiera.

En el siguiente apartado se evalúa otra teoría sobre la guerra que tiene gran relevancia desde la perspectiva de la guerra justa, las motivaciones y lo que sucede cuando estas desaparecen o en definitiva son imposibles de lograr.

\section{Jus ex bello: ¿̨el fin de la guerra?}

La guerra tiene una motivación implícita, ya sea en el enfrentamiento entre Estados o en el conflicto armado interno con grupos al margen de la ley. Siempre se busca un beneficio, la concreción de un interés o del poderío en cualquier aspecto, es por eso que se acude a la violencia como el medio para decidir el ganador y el perdedor. Paralela al cumplimiento del jus ad bellum — justificación de la guerra — y del jus in bello — cumplimiento de las restricciones como protección a la humanidad - se encuentra otra teoría, conocida como jus ex bello, la cual "analiza los aspectos morales de continuar o salir de una guerra en circunstancias en las que la victoria es poco probable" (Murphy, 2017, p. 106).

A diferencia de las anteriores, esta teoría se refiere al desarrollo de la guerra, alejada de normas o presupuestos imperativos que deben cumplir los Estados. El jus ex bello se desarrolla desde la perspectiva moral de las partes en la lucha armada y su evaluación sobre el desenvolvimiento de la violencia en referencia a los objetivos planteados. Por lo tanto, esta teoría apela a un análisis consciente sobre las posibilidades de éxito y la verdadera intención que se tiene al desplegar la violencia, dado que la guerra justa implica, además de los aspectos delimitados en el apartado anterior, la utilización del jus ex bello para evitar conflictos o guerras perpetuas.

Adicionalmente, se debe tener en cuenta que una de las numerosas razones por las cuales se prohíbe la guerra es que debe ser usada como último recurso (Rodríguez, 2006) y no como un recurso disponible. En consecuencia, es inconcebible que no se verifique si la guerra se prolonga para cumplir la causa o si, por el contrario, se mantienen las acciones bélicas sin posibilidades 
de éxito solamente por razones de egos. En este sentido, hay que precisar que la teoría del jus ex bello se encarga de delimitar los fundamentos fácticos de la guerra in situ, por lo tanto, se considera que es intermedia, pues hay otra que se refiere al posconflicto. Específicamente, el jus ex bello posee dos partes: la primera aborda la terminación de la guerra como decisión de las partes o de una sola, mientras que la segunda trata sobre cómo realizarla o de qué manera lograr tal terminación.

No obstante, no hay un criterio cuantificable que permita determinar la finalización de una guerra ni mucho menos hay un manual de terminación por fracaso. Realmente, esta teoría no ha sido explorada del todo por investigaciones jurídicas o que involucren la polemología, sino que se ha desarrollado en investigaciones filosóficas que develan los aspectos morales y las causas, pero solo desarrollan teorías sin formular propuestas sólidas, de manera que la decisión de finalizar un conflicto es empírica y resulta influida por quienes están en la confrontación e incluso por sus asesores. Un ejemplo de la aplicación del jus ex bello es cuando se buscan otros medios de solución a la guerra, como las salidas diplomáticas. $\mathrm{Al}$ respecto, Mollendorf (2008) precisa que se deben cumplir al menos cuatro principios para tomar la decisión de continuar con la guerra, de lo contrario, en definitiva, la terminación sería inminente:

1. Causa justa.

2. Proporcionalidad.

3. Probabilidad de éxito.

4. Búsqueda de remedios diplomáticos (p. 134).

Como se observa, los requisitos del jus ad bellum y el jus ex bello coinciden en la estimación de la causa, pero a esta última se le adiciona la probabilidad de éxito, que, aunque compleja de concretar, es un elemento importante a la hora de sopesar la terminación de la confrontación. Mollendorf (2008) agrega la imposibilidad de establecer si la terminación de la guerra puede ser exitosa, dado que puede tener un efecto adverso en preservar la tranquilidad de la población. Se entiende, entonces, que esta teoría es difusa, posee muchos vacíos y solo puede ser evaluada respecto a casos concretos; es decir, no se puede realizar un análisis deductivo, sino que este debe ser inductivo, enfocado en el contexto y en las causas particulares. 
Adicionalmente, Mollendorf (2015) explica que si se considera injusto continuar con la guerra, esta debería acabar, más aún si no hay relación entre la causa justa para iniciar la guerra y la causa justa para acabarla. El autor denomina este análisis como la tesis de la independencia, por medio de la cual la valoración moral no se puede equiparar desde el móvil inicial versus la imposibilidad de éxito y la decisión de terminar. En suma, los factores iniciales se moldean y cambian, pero no determinan lo justa que puede ser una terminación, con lo cual se entiende que la terminación puede ser catalogada como rendición desde la mirada de los egos de cada Estado o grupo armado.

En definitiva, la idea de finalizar la guerra por éxito poco probable genera diversos cuestionamientos en cuanto a las formas, los motivos, las estrategias y los pasos por seguir. Sin embargo, el jus ex bello es uno de los conceptos más humanos e interesantes en lo que respecta a detener la confrontación y a la moralidad de cada parte: determinar si la guerra debe llegar al fin esperado o si solo conducirá al fracaso y al derroche de recursos que se pudo haber evitado con un final a tiempo, el cual inicia generalmente por una negociación de paz.

\section{Jus post bellum: derecho del posconflicto}

La terminación de la guerra se ha conceptualizado en una teoría denominada jus post bellum, "derecho del posconflicto", la cual tiene como fin último obtener la paz, cuyo concepto antónimo es la guerra. En efecto, según Surasky (2017),

la guerra expresa, en consecuencia, una de las formas de (des)encuentro entre los Estados; la paz, en cambio, no implica necesariamente ningún tipo de encuentro. Es posible estar en paz con un Estado con el que el nivel de relación es lo suficientemente bajo como para entrar en guerra, sin que por ello existan otras formas de relación específicas. (p. 10)

La paz, en consonancia, podría derivarse del no relacionamiento, pues si no existe comunicación o intereses por demostrar poder, las discrepancias son nulas y el relacionamiento es inocuo. Sin embargo, la realidad no es tan idílica en cuanto a las relaciones entre los Estados, y mucho menos entre el Estado y sus ciudadanos, que se pueden armar contra el orden establecido y exigir un 
cambio político o económico, por lo que la paz se alcanza luego del conflicto y el alarmante número de víctimas que se descubre antes y durante la lucha armada. De tal suerte, la obtención de la paz es un asunto vital para esta teoría clásica, considerada como un análisis sobre el momento final de la guerra:

La consideración de este último momento de aplicación de las pautas de la guerra justa fue surgiendo con la reflexión acerca de las consecuencias materiales y sociales de la intervención bélica humanitaria. Se ha ido manifestando, por ello, en una obligación de reconstruir el Estado que ha sido el escenario de la conflagración, una vez concluidas las operaciones militares. Una lenta evolución va abriendo paso a la consagración de dicha obligación en relación con cualquier Estado que participe en acciones bélicas. (Rodríguez, 2014, p. 235)

Siguiendo con esta idea, cabe mencionar que la utilidad del derecho del posconflicto consiste en la obligación de restablecer el daño causado (ArdilaCastro et al., 2020; Atencio Gómez, 2020; Gutiérrez \& Arango, 2019). Sin embargo, la consecución de ese anhelo no es del todo posible, teniendo en cuenta las víctimas, la violación masiva de los DD. HH., el incumplimiento del DiH y el desconocimiento del Dip. En ese sentido, la visión de que es posible restablecer el daño causado es sumamente utópica, dada la imposibilidad de reparar la violación al derecho a la vida, por ejemplo. La obligación entonces se realiza con las víctimas y todo el conjunto de presupuestos sobre la reparación y el reconocimiento de su calidad, dependiente de un marco temporal o la concordancia de los hechos victimizantes.

La doctrina que se ha construido alrededor del jus post bellum se fundamenta en el estudio de las condiciones para el mantenimiento de la paz que establecen organizaciones como la ONU, así como en el análisis de diversos procesos en los cuales se ha pasado de la violencia a la paz, ya sean conflictos entre Estados o conflictos armados internos, alrededor de lo que se ha denominado justicia transicional (JT). Este último concepto hace referencia a un mecanismo que poseen los Estados para reparar a las víctimas de los conflictos armados (Cubides-Cárdenas et al., 2020).

Este paso del conflicto a la paz consiste en

un periodo transicional no clasificable dentro de la guerra ni la paz, sino situado entre ambas. De ahí que la ciencia política y social lo entienda como 
un proceso complejo, largo y difícil, de transformación de la guerra a la paz y con el peligro de recaer. (Añaños, 2011, p. 16)

El riesgo de recaer en las dinámicas conflictivas es uno de los aspectos más complejos de la transición desde que el jus post bellum se formuló primigeniamente en el periodo posterior a la Primera Guerra Mundial. Como se sabe, la transición hacia la paz no tuvo éxito y se desató una nueva guerra, lo cual demuestra que los esfuerzos que se hicieron para poner término a la confrontación bélica no fueron efectivos ni evitaron que se repitiera. En razón al paso del tiempo y a las diferentes formas que ha adoptado la guerra, la justicia transicional ha tenido que adaptarse a cada contexto específico, de manera que no es posible constituir el jus post bellum del mismo modo en todos los conflictos. A pesar de que la teoría tiene cimientos estructurales y fácticos similares, es necesario que los procesos de transición se adecúen a las víctimas, los actores, las necesidades y las obligaciones de las partes.

Si bien el término posee gran importancia, solo hasta hace relativamente muy poco se ha consolidado de manera general (Gómez, 2013), por lo cual los procesos de transición anteriores no se realizaron de acuerdo con los postulados doctrinales de la JT, aunque sí recogen consideraciones similares en razón al proceso y su esencia. Tales procesos están dotados de diversos componentes que priorizan necesariamente a las víctimas y, como se mencionó, abarcan la obligación de lograr — en medida razonable — que las cosas vuelvan al estado anterior, o al menos que se repare a quien padeció en razón de la guerra.

La instancia del jus post bellum "implica llevar a juicio a los perpetradores, revelar la verdad acerca de crímenes pasados, brindar reparaciones a las víctimas, reformar las instituciones abusivas y promover la reconciliación" (Van Zyl, 2011, p. 47). Ese es el objetivo principal, en cuyo cumplimiento se evita a toda costa cualquier tipo de impunidad, puesto que la salida negociada del conflicto $^{8}$ no puede derivarse en la cesación de la persecución penal o el perdón colectivo de los perpetradores de las violaciones masivas a los DD. HH., más aún cuando los delitos configurados son delitos de lesa humanidad o crímenes de guerra.

8 Sobre la salida negociada del conflicto desde el caso colombiano, véase Melamed (2017). 
Por tanto, la terminación del conflicto y la etapa posterior es de especial atención, pues se debe evitar por todos los medios que las víctimas sean nuevamente victimizadas por trámites absurdos o procesos improvisados que no se fundamentan en postulados claros. Además, aunque no existe una figura normativa que especifique la manera en la que los Estados deben realizar los procesos de transición en la etapa de posconflicto, diversos lineamientos de organismos internacionales y la doctrina consolidada han sido una guía útil a los Estados que en esta década se enfrentan a procesos de transición, ya sea por un conflicto armado interno, como es el caso colombiano, o por la transición de una dictadura hacia la democracia, como fue el caso de Argentina (Rauschenberg, 2018).

Ahora bien, uno de los principales conceptos y baluartes de la JT son las reparaciones a las víctimas para resarcir el daño causado. No obstante, la amplitud del concepto hace que en ocasiones la herramienta de reparación que abandera el proceso de transición no sea correcta. Según De Greiff (2011), la reparación puede adoptar distintas formas de acuerdo con el derecho internacional:

Restitución, que se refiere a aquellas medidas que buscan restablecer el statu quo de la víctima. Estas medidas van desde la restauración de derechos tales como la ciudadanía y la libertad, pasando por la restitución del empleo y otros beneficios, hasta la restitución de propiedades.

Compensación, que se refiere a aquellas medidas que buscan compensar los daños sufridos a través de la cuantificación de los daños, donde el daño se entiende como algo que va mucho más allá de la mera pérdida económica e incluye la lesión física y mental y, en algunos casos, también la lesión moral.

Rehabilitación, que se refiere a medidas que proveen atención social, médica y psicológica, así como servicios legales.

Satisfacción y garantías de no repetición, que constituyen categorías especialmente amplias, pues incluyen medidas tan disímiles como el cese de las violaciones, verificación de hechos, disculpas oficiales y sentencias judiciales que restablecen la dignidad y la reputación de las víctimas, plena revelación pública de la verdad. (pp. 408-409)

La variedad de maneras mediante las cuales se puede reparar a la víctima es una prueba fehaciente de la enorme responsabilidad que implica un proceso de 
transición cuando la guerra acaba, pero el flagelo de las víctimas sigue intacto. Es por ello que las teorías clásicas que se han consolidado en el tiempo han logrado que los efectos de la guerra no pasen inadvertidos y han contribuido a evitar que la humanidad sea la víctima por excelencia de confrontaciones absurdas que responden a intereses individuales. Asimismo, en el eventual caso en que existan víctimas, estas teorías abogan por que sean reparadas y no se olvide su importancia en la construcción de la paz y las transformaciones de toda índole que la posibiliten, fin último de la JT: la terminación de la guerra y su no repetición.

\section{Cesación de la lucha armada en Colombia, la dualidad entre posacuerdo y posconflicto}

El escenario de la JT y todos los procesos que se surten en razón al cumplimiento de los acuerdos de paz constituyen la materialización del jus post bellum en Colombia y su conflicto armado.

\footnotetext{
El acuerdo final para la terminación del conflicto y la construcción de una paz estable y duradera que firmaron el gobierno colombiano y las Fuerzas Armadas Revolucionarias de Colombia-Ejército del Pueblo (FARC-EP) ha sido uno de los sucesos políticos más importantes del país en los últimos años, toda vez que permitió iniciar la transición del conflicto armado hacia un escenario de paz y concordia después de más de cincuenta ańos de violencia. (FernándezOsorio, 2019, p. 105)
}

En efecto, como lo refiere el autor, el proceso transitivo nace a partir de la firma del acuerdo de paz con una de las guerrillas más antiguas de la historia, con la que solo existieron desencuentros en lo que respecta a la cesación de la lucha armada, por lo cual el proceso tiene un pasado lleno de tropiezos y de falta de voluntad de las partes. Sin embargo, pese al funesto prontuario de intentos, en el año 2016 se logró un acuerdo por medio del cual este grupo abandonaba su lucha armada y se integraría a la sociedad. Con la utilización de diversos mecanismos, como la Comisión de la Verdad o la Unidad de Búsqueda de Personas Dadas por Desaparecidas, los postulados negociados entre las partes tienen cabida en el país en el ordenamiento jurídico, que ha generado todo un blindaje por medio de actos legislativos, leyes y decretos para que la transición se dé, sin que las voluntades políticas de turno lo impidan. 
La etapa que sigue luego de la terminación del conflicto suele llamarse posconflicto. Sin embargo, ante la observación detallada de la realidad colombiana y las dinámicas conflictivas que aún persisten por la existencia de más grupos al margen de la ley, se debe afirmar que el país no se encuentra en una instancia de posconflicto. Pese a que el concepto es inacabado y no hay armonía en su definición, la distinción teórica es clara y la realidad que se evidencia en Colombia apunta a una etapa de posacuerdo, en la que lo negociado se encuentra aún en implementación (Niño \& Palma, 2019). Es más evidente tal afirmación si se identifica la situación de desmovilización y de falta de voluntad de los grupos disidentes, que no se acoplaron al proceso, sino que se reagruparon y constituyen una nueva amenaza a la seguridad nacional (Sierra-Zamora et al., 2020), lo cual ha debilitado aún más el tambaleante proceso que parece no avanzar.

Es así como la precisión conceptual es importante, pero no desde una perspectiva fatalista o poco optimista con el proceso. Todo lo contrario, el uso correcto de los términos empalmados con la realidad es necesario para tener una visión realista de la transición y no caer en falsas expectativas, que solo traen efectos nocivos y se desligan de lo que verdaderamente constituye la etapa posterior al conflicto, en donde la transformación y la reconstrucción del tejido social es evidente. Además, se debe tener en cuenta que las dinámicas que se han configurado durante más de medio siglo no van a ser superadas en un corto periodo, por lo que resulta prioritario cuidar el proceso y todo lo concerniente al cumplimiento del jus post bellum, sin importar que exista desacuerdo o que se desee truncar una consolidación que Colombia adeuda a sus ciudadanos hace muchos años.

Es por ello que las instancias de la guerra son tambaleantes realidades que deben ser atendidas con especial detenimiento y experticia, pues de lo contrario terminan en una suma de fracasos. Por tanto, más allá de evidenciar un problema en el panorama genérico y específicamente en el Estado colombiano, la intención de esta investigación es analizar las teorías existentes, los términos y las normas, así como la forma en que se materializa su uso. Por supuesto, todos estos postulados no mueren en el papel ni la realidad se adecúa a lo que formulan, de manera que valorar estos temas desde múltiples perspec- 
tivas es una tarea enriquecedora, pues la guerra y el conflicto son inherentes a la condición convulsionada de la humanidad, que cambia, pero se mantiene la violencia como la solución más rápida y concluyente.

\section{Ética militar y su relación con la guerra justa}

Cuando se aborda el conflicto, la guerra o la lucha armada, la visibilización de las partes suele reducirse a desencuentros políticos, sociales, económicos, poblacionales, territoriales o cualquier otro hecho de la sociedad que amerite un debate que nunca pudo conciliarse. Por tanto, quienes ostentan la tarea de materializar la fuerza legítima del Estado, esto es, las Fuerzas Militares o el Ejército, deben adecuarse a los deseos de su Estado, bien sea iniciar una guerra o responder a actos que configuran una amenaza. Desde esta realidad, el soldado se encuentra en obligación de cumplir con los presupuestos del Din priorizando a la población civil. Además, en el Ejército se espera de este rol rasgos especiales como la lealtad, la obediencia y la disciplina, así como la valentía (Gómez, 2017), que en parte es un elemento diferenciador en el conflicto.

Por tanto, la ética militar como aspecto de especial importancia en la guerra justa se fundamenta en el cumplimiento de rasgos y comportamientos esperados (Moliner, 2018), independientemente de la lucha armada o el triunfo. Son los valores castrenses los que deben primar y ser la carta de presentación de cada unidad que va a combate, como muestra de ética militar, sin que el poder armamentístico constituya el fundamento de la actuación, sino que la estrategia y la suficiente instrucción deben primar en la conducción de la guerra, de tal manera que se enaltezca cada uno de los pilares que agrupan las doctrinas militares.

\section{Conclusión}

Las teorías clásicas de la guerra, su desarrollo en el tiempo y su reforma en razón a los contextos son un esfuerzo por evitar que la fuerza sobrepase la dignidad humana o el respeto a la paz cuando se inician guerras caprichosas 
o que no están entre las posibilidades que reguló la OnU. Por ello, cada uno de los jus no solo evidencia la responsabilidad internacional, sino que además demuestra a la comunidad académica que la guerra se sigue perpetuando y que su paso es inexorable, a pesar de los cientos de normas compendiadas que la regulan y de que haya sido prohibida. Para el Estado, el paso de la guerra adquiere distintas connotaciones y desenlaces, pero el cumplimiento de los presupuestos de la guerra justa y humanizada no distingue el tipo de conflicto o la ubicación geográfica, lo cual representa un desafío a la manera en la que las normas se redactan y lo que su incumplimiento acarrea.

$\mathrm{Al}$ aterrizar los postulados en Colombia, en específico el jus post bellum, se demuestra que a pesar de las intenciones claras de transitar a un contexto de paz, las situaciones que se presentan en el país dificultan que se cumpla ese deseo y lo convierten en una utopía, que en definitiva debe superarse para evitar a toda costa que las negociaciones y la normatividad sea otro fracaso a la cuenta de procesos fallidos. Asimismo, se debe tener en cuenta que las Fuerzas Armadas son una de las partes más visibles del conflicto y que no solo tienen la obligación de respetar a la población y cumplir el DiH, sino que además deben cumplir a cabalidad la misión de la institución castrense orientadas por la ética militar, la guerra justa y la materialización de las teorías y su impacto.

\section{Referencias}

Abello, I. (2003). El concepto de la guerra en Foucault. Revista de Estudios Sociales, (14), 71-75. https://doi.org/10.7440/res14.2003.06

Añaños, M. (2011). La consolidación de la paz en el derecho internacional. Revista Electrónica de Estudios Internacionales, 43(168), 51-86. https://revistaei.uchile.cl/index.php/REI/ article/view/14337

Ardila-Castro, C. A., Ramírez-Benítez, E., \& Cubides-Cárdenas, J. (2020). El derecho internacional humanitario y su significado para las operaciones militares presentes y futuras. Revista Cientifica General José María Córdova, 18(32), 857-882. https://doi. org/10.21830/19006586.697

Arratia-Sandoval, E., Jiménez-Cabrera, D., \& Barria-Jorquera, A. (2020). ¿El fin justifica los medios? Las FARC y el narcotráfico como delito conexo. Revista Cientifica General José Maria Córdova, 18(32), 841-856. https://doi.org/10.21830/19006586.608

Atencio Gómez, M. S. (2020). Los derechos de las mujeres víctimas del conflicto armado colombiano. Revista Científica General José María Córdova, 18(30), 401-415. https://doi. org/10.21830/19006586.584 
Bartolomé, M. (2017). El empleo actual del concepto guerra en las relaciones internacionales. Revista de Relaciones Internacionales, Estrategia y Seguridad, 12(2), 43-66. https:// www.redalyc.org/articulo.oa?id=927/92751348003

Bellamy, A. (2009). Guerras justas, De Cicerón a Irak. Fondo de Cultura Económica.

Bosemberg, L. (2006). Las guerras mundiales: problemas y controversias en torno a los orígenes. Anuario Colombiano de Historia Social y de la Cultura, (33), 289-309. https://www. redalyc.org/pdf/1271/127112581011.pdf

Castañeda, F. (2003). Sobre la posibilidad de la guerra justa entre fieles y paganos en Tomás de Aquino. Revista de Estudios Sociales, (14), 26-37. http://journals.openedition.org/ revestudsoc/26440

Clausewitz, C. (1992). De la guerra. Labor.

Comité Internacional de la Cruz Roja. (2005). Derecho Internacional Humanitario: Respuestas a sus preguntas. CICR. https://www.icrc.org/es/doc/assets/files/other/icrc_003_0703.pdf

Cubides-Cárdenas, J., Sierra-Zamora, P., \& Tirano, P. (2020). Justicia transicional y comisiones de la verdad: Una mirada desde el ente internacional y el Acuerdo de Paz de Colombia. En Cubides-Cárdenas \& Sierra-Zamora (eds.), Seguridad, Justicia y Derechos Humanos: La superación del conflicto colombiano y su dimensión internacional (pp. 85-104). Sello Editorial ESMIC.

Cuenca, R., Muñoz, A., Beltrán, J., \& Sarmiento, J. (2018). Ius in bellum. Universidad Manuela Beltrán. https://www.umb.edu.co/libros-editorial-UMB/ius-in-bellum-universidad-manuela-beltran.pdf

De Greiff, P. (2011). Justicia y reparaciones. En F. Reátegui (ed.), Justicia transicional: Manual para América Latina (pp. 407-440). Centro Internacional para la Justicia Transicional (ICJT).

Fernández-Osorio, A. (2019). La implementación del Acuerdo de Paz con las FARC-EP: Un estudio comparado desde la experiencia internacional. Análisis Político, 32(95), 104-124. https://doi.org/10.15446/anpol.v32n95

Flórez, J. (2011). ¿Estado o concepto fallido? Problemas que plantea la noción de falla estatal y los índices que intentan medirla. Revista Derecho del Estado, (27), 193-234. http:// www.scielo.org.co/scielo.php?script=sci_arttext\&pid=S0122-98932011000200010\&ln$\mathrm{g}=\mathrm{en} \& \mathrm{t} \operatorname{lng}=\mathrm{es}$

Giraldo, J. (2008). Rawls, la validación de la guerra justa. Co-herencia, 5(8), 39-64. http:// www.scielo.org.co/scielo.php?script=sci_arttext\&pid=\$1794-58872008000100002\&ln$\mathrm{g}=\mathrm{en} \& \mathrm{t} \operatorname{lng}=\mathrm{es}$

Gómez, G. (2013). Justicia transicional "desde abajo": Un marco teórico constructivista crítico para el análisis de la experiencia colombiana. Co-herencia, 10(19), 137-166. http://www. scielo.org.co/pdf/cohe/v10n19/v10n19a06.pdf

Gómez, G. (2017). Riesgos de transgresión moral del militar en la posmodernidad [Tesis de doctorado, Universitat de Barcelona]. Repositorio institucional. https://www.tdx.cat/ bitstream/handle/10803/461356/GAGR_TESIS.pdf?sequence $=1$

Grocio, H. (1925). Del derecho de la guerra y la paz. Reus. http://fama2.us.es/fde/ocr/2010/ delDerechoDeLaGuerraYDeLaPazT1.pdf 
Gurmendi., A. (2013). Lucha contrasubversiva en el Perú: ¡conflicto armado o delincuencia terrorista? Themis, Revista de Derecho, (63), 109-129.

Gutiérrez Felipe, R., \& Arango Morales, X. A. (2019). Percepción ciudadana de los Derechos Humanos: el caso de Monterrey, Nuevo León. Revista Cientifica General José María Córdova, 17(25), 131-145. https://doi.org/10.21830/19006586.138

Henckaerts, J. (2005). Estudio sobre el derecho internacional humanitario consuetudinario: Una contribución a la comprensión y al respeto del derecho de los conflictos armados. International Review of the Red Cross, 87(857). https://www.icrc.org/es/doc/assets/ files/other/icrc_003_0860.pdf

Hernández, A. (2000). Uso de la fuerza en el derecho internacional: Aplicación en conflictos internos. Agenda Internacional, 7(15), 161-181. http://revistas.pucp.edu.pe/index.php/ agendainternacional/article/view/7272

Jiménez-Reina, J., Gil-Osorio, J. F., \& Jiménez-Reina, R. (2021). El derecho operacional en relación con los Derechos Humanos y el Derecho Internacional Humanitario. Revista Cientifica General José María Córdova, 19(33), 115-131. https://doi.org/10.21830/19006586.655

Jiménez Villarreal, J. E., \& Jiménez Montalvo, D. A. (2019). Violencia sexual en zonas de posconflicto: Reflexiones en torno al caso de la República Centroafricana. Revista Cientifica General José María Córdova, 17(27), 505-523. https://doi.org/10.21830/19006586.436

Kant, E. (1979). La paz perpetua (7. a ed.). Espasa Calpe.

Kolb, R. (1997). Origen de la pareja terminológica ius ad bellum / ius in bello. Revista Internacional de la Cruz Roja, 558-598. https://international-review.icrc.org/sites/ default/files/S0250569X00004283a.pdf

Legris, M. (2016). Repensando el ius ad bellum y el ius in bello: Hacia un estudio de su relación en el contexto de un derecho internacional fragmentado. En Buis \& Luterstein (eds.), La guerra ante la fragmentación del derecho internacional: Interacciones, intercambios, interferencias (pp. 34-45). Académica Sempithidia.

Melamed, J. (2017). La justicia transicional: La llave hacia una salida negociada al conflicto armado en Colombia. Revista de Relaciones Internacionales, Estrategia y Seguridad, 12(1), 185-206. http://dx.doi.org/10.18359/ries.2469

Mercado, A., \& González, G. (2007). La teoría del conflicto en la sociedad contemporánea. Espacios Públicos, 11(21), 196-221. https://www.redalyc.org/pdf/676/67602111.pdf

Miron, M. (2020). The 'strategy bridge' as the forgotten dimension of effective COIN: the case of Peru and Sendero. Small Wars \& Insurgencies, 31(1), 159-180.

Moliner, J. (2018). ¿Qué es la ética militar? Documento marco. Instituto Español de Estudios Estratégicos. http://www.ieee.es/Galerias/fichero/docs_marco/2018/DIEEEM16-2018_ EticaMilitar_JAMoliner.pdf

Mollendorf, D. (2008). Jus ex bello. The Journal of Political Philosophy, 16(2), 123-136. https://www.fb03.uni-frankfurt.de/58976166/jus-ex-bello.pdf

Mollendorf, D. (2015). Two doctrines of jus ex bello. Ethics, 125(3), 653-673.

Murphy. J. (2017) Pensamiento de guerra justa y la noción de paz. En F. Demont-Biaggi (ed.), La naturaleza de la paz y la moralidad del conflicto armado (pp. 105-122). Palgrave Macmillan. https://doi.org/10.1007/978-3-319-57123-2_6 
Niño, C., \& Palma D. (2019). Colombia en mutación: del concepto de posconflicto al pragmatismo del conflicto. JANUS.NET e-Journal of International Relations, 9(2), 82-97. https://doi.org/10.26619/1647-7251.9.2.6

Organización de las Naciones Unidas. (2011). Protección jurídica internacional de los Derechos Humanos durante los conflictos armados. Oficina del Alto Comisionado. https://www.ohchr.org/documents/publications/hr_in_armed_conflict_sp.pdf

Peytrignet, G. (1995). Derecho Internacional Humanitario: Evolución histórica, principios esenciales y mecanismos de aplicación. Instituto Interamericano de Derechos Humanos. http://ru.juridicas.unam.mx:80/xmlui/handle/123456789/24603

Puyana, G. (2003). Teorías de la guerra en Moltke y Liddell Hart. Revista de Estudios Sociales, 15, 109-121. http://journals.openedition.org/revestudsoc/26136

Rauschenberg, N. (2018). Justicia y verdad en la transición argentina. Notas sobre el lugar de la memoria ejemplar. Entramados y Perspectivas. Revista de la Carrera de Sociología, 8(8), 298-332.

Rodríguez, E. (2014). Guerra justa. Eunomía. Revista en Cultura de la Legalidad, 6, 224-237.

Rodríguez, F. (2006). Nuevos tipos de guerra: Lecciones a considerar, guerra justa, asimétrica, preventiva y de baja intensidad. Si Somos Americanos, Revista de Estudios Transfronterizos, 8(2), 135-157. https://www.redalyc.org/articulo.oa?id=3379/337930325008

Ruiz, X. (2003, mayo). El ius ad bellum en la crisis de Irak. Unisci Discussion Papers [Universidad Complutense de Madrid]. https://www.ucm.es/data/cont/media/www/ pag-72539/Xira2.pdf

Salmón, E. (2004). Introducción al Derecho Internacional Humanitario. Pontificia Universidad Católica del Perú.

Santiago, T. (2004). Kant y su proyecto de una paz perpetua (en el bicentenario de su muerte). Revista Digital Universitaria, 5(11), 1-11. http://www.revista.unam.mx/vol.5/num11/ art77/int77.htm

Sarmiento-Hernández, E. A., Rojas-Guevara, J. U., \& Rojas-Guevara, P. J. (2020). Incidencia del proceso de paz con las FARC en la política antidrogas de Colombia. Revista Cientifica General José María Córdova, 18(32), 817-837. https://doi.org/10.21830/19006586.632

Sierra-Zamora, P. (ed.). (2020). El conflicto armado, el acuerdo de paz y la justicia transicional. El caso colombiano. Ibáńez.

Sierra-Zamora, P., Fonseca, T., \& Mejía, J. (2020). Modernización y reestructuración de la seguridad y defensa nacional: Análisis propositivo para una ley de seguridad y defensa en Colombia. En Sierra \& Bermúdez (eds.), Evaluación jurídica de la seguridad y defensa nacional como política de Estado (pp. 247-268). Planeta.

Silva, L. (2008). La guerra y la paz en Kant y Hegel, un problema político. Criterios: Cuadernos de Ciencias Jurídicas y Política Internacional, 1(2), 15-37.

Surasky, J. (2017). Polemología y derecho humano al desarrollo: Clausewitz y la cooperación internacional. IUS: Revista del Instituto de Ciencias Jurídicas de Puebla, 11(40), 7-27. http://www.scielo.org.mx/pdf/rius/v11n40/1870-2147-rius-11-40-00007.pdf 
48 Volumen I. Ética militar y fundamentación profesional. Evolución, conceptos y principios

Van Zyl, P. (2011). Promoviendo la justicia transicional en sociedades post conflicto. En Reátegui (ed.), Justicia transicional: Manual para América Latina (pp. 47-72). Centro Internacional para la Justicia Transicional (ICJT).

Vargas, S., Jaramillo, J., \& Ríos, M. (2013). Tratamiento normativo al status de beligerancia y terrorismo dentro del conflicto armado en Colombia. Inciso, (15) 9-26. https://revistas. ugca.edu.co/index.php/inciso/article/view/70

Walzer, M. (2011). Guerras justas e injustas. Un razonamiento moral con ejemplos históricos. Paidós. 